\title{
Correction to: Effect of Biological Cementation on the Mechanical Behaviour of Dredged Soils with Emphasis on Micro-structural Analysis
}

\author{
K. M. N. Saquib Wani ${ }^{1}$ (D) B. A. Mir ${ }^{1}$ (D)
}

Published online: 9 March 2020

๑) Springer Nature Switzerland AG 2020

\section{Correction to: \\ International Journal of Geosynthetics and Ground Engineering (2019) 5:32 \\ https://doi.org/10.1007/s40891-019-0183-9}

The complete source details regarding permission for reproducing the images were missing in the original publication and are included in this erratum. In the original publication, Figs. 2, 3, 4, 5, 11a-d, were reprinted from the paper 'Influence of Microbial Geo-technology in the Stabilization of Dredged Soils' by K. M. N. Saquib Wani and B. A. Mir, International Journal of Geotechnical Engineering, pp. 1-10, https://doi.org/10.1080/19386362.2019.1643099 by permission of the publisher (Taylor \& Francis Ltd, http:// www.tandfonline.com). This was done by the authors in view of the continuity of their $\mathrm{PhD}$ research progress on a specific site location for a set of experimental variables and parameters.

Publisher's Note Springer Nature remains neutral with regard to jurisdictional claims in published maps and institutional affiliations.

The original article can be found online at https://doi.org/10.1007/ s40891-019-0183-9.

K. M. N. Saquib Wani

sakibwani_02phd17@nitsri.net; sakibwani17@gmail.com

B. A. Mir

p7mir@nitsri.net; bamiriitb@gmail.com

1 Department of Civil Engineering, National Institute

of Technology, Srinagar, J\&K 190006, India 